\title{
Research Article \\ Effects of Recycled Aggregate on Concrete Mix and Exposure to Chloride
}

\author{
Ammar Ben Nakhi and Jasem M. Alhumoud 1 \\ Civil Engineering Department, College of Engineering and Petroleum, Kuwait University, Kuwait City, Kuwait \\ Correspondence should be addressed to Jasem M. Alhumoud; jalhumoud@yahoo.com
}

Received 7 March 2019; Accepted 4 June 2019; Published 25 June 2019

Academic Editor: Ali Nazari

Copyright (c) 2019 Ammar Ben Nakhi and Jasem M. Alhumoud. This is an open access article distributed under the Creative Commons Attribution License, which permits unrestricted use, distribution, and reproduction in any medium, provided the original work is properly cited.

\begin{abstract}
Construction and demolition waste has dramatically increased in the last decade, and most of it goes into landfills, increasing the burden on landfill loading and operations. Recycling of concrete is needed from the viewpoints of environmental preservation and effective utilization of resources. Regarding the durability of concrete, chloride diffusion, which is one parameter that reflects the durability of concrete, is tested in this study. Concrete made with different percentages of recycled aggregate $(0 \%-100 \%$, with increments of 10\%) is investigated using mechanical and nondestructive testing of mixes consisting of two aggregate particle sizes $\left(1 / 2^{\prime \prime}\right.$ and $\left.3 / 8^{\prime \prime}\right)$. In addition, we studied the chloride diffusion of saturated concrete made with different percentages of recycled aggregate. The samples were exposed to sea water with $3 \%$ chloride concentration and tested after 2 and 4 weeks of exposure. The results indicate that the density and air content of new concrete decreased with an increase in recycled aggregates content. Compressive strength decreased with the increase in the recycled aggregate content, and a concrete mix with $40 \%$ recycled aggregate exhibited the best strength. Concrete mix with 30\% recycled aggregate had the lowest chloride penetration after 2 weeks of saturation and performed better than a concrete mix with $100 \%$ natural aggregate. Owing to the lower density and higher water absorption of recycled aggregates, chloride ion diffusion increased with increasing recycled aggregate content beyond 2 weeks.
\end{abstract}

\section{Introduction}

Construction and demolition (C\&D) waste is one of the largest waste flows in the world. Disposal of C\&D waste is not only an environmental concern but also has a major influence on the conservation of natural resources by avoiding excavation of raw material. Most of this waste goes into landfills, increasing the burden on landfill loading and operations. Some noninert waste materials in C\&D waste (such as lead, tar, asbestos, paint, and preservative residues) may introduce environmental hazards over time [1]. Instead, recycling presents an opportunity to dispose of concrete and other nonhazardous waste.

Recycling is one of the strategies toward minimizing waste and offers many benefits-reducing the demand for new resources, cutting down on transport and production energy costs, using waste which would otherwise be lost to landfill sites [2], preserving areas of land for future urban development, improving the general state of the environment [3], and sustaining more jobs than would be available by treating the same amount of materials at traditional landfills [1].

According to Kartam et al. [4], there are four factors affecting C\&D waste recycling. First is the purity of recycled material. Choosing between recycling and other appropriate disposal methods is determined by the concentrations of harmful substances in recycled C\&D materials. Second is the cost of collection and transport. Third is the cost of sorting, transformation into reusable material, and the disposal costs of any residual material to landfills or incineration. Finally, it is necessary that recycled materials meet the pertinent required specifications and standards.

Recycled aggregate is necessary because of the high consumption of raw materials needed to make concrete and because of the current high level of worldwide construction activities. By recycling concrete waste aggregates and using them as a source for producing new concrete, an alternate source of aggregate production is available. The environmental impact of the production of coarse aggregate led 
Kuwait's local Environment Public Authority in 1997 to ban its production from local quarries [5].

The volume of construction waste in Kuwait was estimated at 4.1 million tons at a rate of 11,000 tons per day in 2010, which is considered high compared to international figures, probably due to the high level of construction activities after the Gulf war and to poor materials management by the Kuwaiti construction industry. C\&D waste in Kuwait is produced from the following activities: demolition of old buildings, material left over from new construction, building maintenance, and manufacturing debris [4].

Thomas et al. [6] found that because the water absorption of recycled aggregate is higher than that of natural aggregate, especially when the recycled aggregate is dry before mixing, the amount of water required to mix the concrete properly must be increased.

Abdel-Hay [7] studied three groups of mixes containing different water to cement ratios (w/c), and each of these groups involved five mixes with different amounts of recycled aggregate. The authors found that all the concrete mixes had low workability, and the workability decreased with increasing percentage of recycled aggregate content because of the high-water absorption of the recycled aggregate and its rough surface texture.

Poon et al. [8] studied four groups of concrete mixes: $100 \%$ natural aggregate, $20 \%$ recycled aggregate, $50 \%$ recycled aggregate, and 100\% recycled aggregate. Each group used three mixes: the first with air-dried (AD) aggregate, the second with oven-dried (OD) aggregate, and the last with saturated surface dry (SSD) aggregate. This study was used to test the slump and the strength of the recycled aggregate concrete mixes. The authors concluded that the amount of recycled aggregate in the concrete mix had a low effect on initial slump for the mixes containing recycled aggregate in the SSD condition, while the mixes containing a large amount of $\mathrm{AD}$ and $\mathrm{OD}$ recycled aggregate would require a large amount of water, which resulted in high initial slump [9].

Muduli and Mukharjee [10] found that recycled aggregate concrete mix has higher air content than natural aggregate concrete mix. Falek et al. [11] concluded that the relationship between the density and the amount of fine recycled aggregate in concrete mixes is an inverse relationship; when the proportion of fine recycled aggregate increases, the density of the concrete mix decreases. This is because of the low density of the fine recycled aggregate compared to the density of the crushed fine stone and because the aggregate to cement ratio has an insignificant effect on concrete density.

Lovato et al. [12] found that an increase of the recycled aggregate content (fine (FRA), or coarse (CRA)), tends to reduce the concrete's resistance, which is not desirable. The highest resistances are exhibited by concretes without recycled aggregates. When $100 \%$ FRA or CRA are added to the mixture, the concrete's resistance is reduced by $18 \%$ and $24 \%$, respectively. When working with $100 \%$ substitution of natural aggregates by recycled ones, a resistance reduction of approximately $20 \%$ was found for low w/c ratios $(0.45)$ in concretes with $100 \%$ FRA or $100 \%$ CRA.
According to Thomas et al. [6], concrete with 100\% coarse recycled aggregate showed a reduction in compressive strength between $9 \%$ and $45 \%$. Puthussery et al [13] concluded that the compressive strength decreased with the increase of fresh concrete waste (FCW) aggregate content in both series of concrete mixes that were evaluated.

Maslehuddin et al. [14] confirmed that Type I concrete (concrete with normal cement) is more resistant to chloride diffusion than Type V (concrete with high sulfate resistance) and demonstrated that adding silica fume improves the performance of concrete. They also found that the chloride concentration accelerates reinforcement corrosion, and as chloride concentration increases, the corrosion current density $\left(I_{\text {corr }}\right)$ increases, resulting in higher weight loss of the material due to corrosion. Verian et al. [15] observed that the diffusion coefficient decreases with time until it eventually reaches a stable value. Zhang and Gjorv [16] concluded that chloride diffusivity is inversely proportional to the square root of the chloride source concentration in a diluted solution, whereas both conductivity and diffusivity are inversely proportional to the cubic root of the chloride source concentration in a concentrated solution (general solution). Moreover, the diffusion of chloride was more dependent on the concentration at lower concentration levels. Puthussery et al. [13] observed that the use of FCW aggregate decreased the resistance to chloride ion penetration by the concrete. This may also be related to FCW aggregate having higher porosity than natural granite aggregate. Olorunsogo and Padayachee [17] presented a wide range of experimental results on acid soluble chloride diffusion for different mixes of concrete. They showed that the effective chloride transport coefficient is strongly dependent on the period of exposure of concrete to a chloride environment. Neves et al. [18] and Buhamad [19] found that chloride conductivity increased with increases in the replacement levels of RA for a given curing duration of concrete mixes. However, longer curing duration decreased the conductivity of the concrete mix for any given RA level. Xiao et al. [20] found that the chloride diffusion process is also influenced by the RA shape to some extent. The higher the number of equilateral polygons of RA, the lower the effective chloride diffusion $\left(D_{\text {eff }}\right)$ is, meaning regulation of RA can reduce the $D_{\text {eff }}$ of the RAC model. In addition, the variation of chloride concentration on concrete boundaries can also affect the diffusion process and diffusivity of chloride. Diffusion involving larger chloride concentrations on the boundary in the middle is more favorable than on either end for the same chloride concentration [21].

\section{Objective}

In this paper, concrete made with different percentages of recycled aggregate $(0 \%-100 \%$, in increments of $10 \%)$ are investigated using mechanical and nondestructive testing for two particle sizes: $1 / 2^{\prime \prime}$ and $3 / 8^{\prime \prime}$. The experimental observations and subsequent explanations of recycled aggregate concrete behavior under compressive strain are presented. In addition, we studied the chloride diffusion of saturated concrete made with different percentages of recycled 
TABLE 1: Mix design.

\begin{tabular}{|c|c|c|c|c|c|c|c|c|c|c|c|}
\hline & \multicolumn{11}{|c|}{ Percentage of recycled aggregates } \\
\hline & 0 & 10 & 20 & 30 & 40 & 50 & 60 & 70 & 80 & 90 & 100 \\
\hline Cement & 19.32 & 19.32 & 19.32 & 19.32 & 19.32 & 19.32 & 19.32 & 19.32 & 19.32 & 19.32 & 19.32 \\
\hline Natural coarse aggregate $1 / 2^{\prime \prime}$ & 27.64 & 24.42 & 21.32 & 18.33 & 15.44 & 12.65 & 9.95 & 7.34 & 4.82 & 2.37 & 0 \\
\hline Natural coarse aggregate $3 / 8^{\prime \prime}$ & 27.64 & 24.42 & 21.32 & 18.33 & 15.44 & 12.65 & 9.95 & 7.34 & 4.82 & 2.37 & 0 \\
\hline Recycled coarse aggregate $1 / 2^{\prime \prime}$ & 0 & 2.71 & 5.33 & 7.86 & 10.29 & 12.65 & 14.93 & 17.13 & 19.26 & 21.33 & 23.33 \\
\hline Recycled coarse aggregate $3 / 8^{\prime \prime}$ & 0 & 2.71 & 5.33 & 7.86 & 10.29 & 12.65 & 14.93 & 17.13 & 19.26 & 21.33 & 23.33 \\
\hline Sand & 40.86 & 40.54 & 40.23 & 39.94 & 39.65 & 39.37 & 39.11 & 38.85 & 38.60 & 38.36 & 38.13 \\
\hline Water & 12.66 & 12.93 & 13.19 & 13.44 & 13.68 & 13.91 & 14.14 & 14.36 & 14.57 & 14.77 & 14.97 \\
\hline
\end{tabular}

aggregate. The samples were exposed to sea water with $3 \%$ chloride concentration (normal chloride concentration in sea water) and tested after 2 and 4 weeks of exposure. Moreover, the workability of the fresh concrete and the strength of the hardened concrete were investigated. Finally, slump, air content, and concrete density were tested for the fresh concrete, while the compressive strength was tested for the hardened concrete after 28 days.

\section{Experimental Procedures}

Different tests were carried out for the sand, recycled aggregate, and the natural aggregate before designing the concrete mix. The purpose of the tests was to measure bulk oven-dry specific gravity, absorption, oven-dry rodded density, and moisture content for fine aggregates, natural coarse aggregates, and recycled aggregates. The absolute volume method was used for designing the concrete mix. The concrete mix was designed using natural and recycled coarse aggregates of two particle sizes $\left(1 / 2^{\prime \prime}\right.$ and $\left.3 / 8^{\prime \prime}\right)$. The mix proportions are shown in Table 1.

After the mix design was completed, the concrete components were mixed in a blender. For each concrete mix, the slump, air content, and concrete density were tested for the fresh concrete. The fresh concrete was cast into cubes with dimensions of $15 \times 15 \times 15 \mathrm{~cm}^{3}$, weighing $2.5 \mathrm{~kg}$ each. Twelve cubes were made for each of the eleven different mixes with different percentages of aggregates ( $0 \%$ to $100 \%)$ for a total of 132 cubes.

The samples were soaked in water until the day of testing. Three cubes of each mix were used to measure the compressive strength after 28 days using a compressive strength test machine. The other nine cubes were removed from the water and were allowed to dry naturally for one day. Five faces of each cube were then coated with insulator and one face was left bare, and then all cubes were left out to dry for one day. On the following day, the cubes were coated with another layer of insulator and again left out to dry for another day. After drying, the cubes where placed in water until fully saturated. Then, the cubes were placed in a tank of sea water with $3 \%$ chloride concentration after coating and were tested after 2 and 4 weeks. The purpose of coating the cubes in this matter is to study and investigate the chloride diffusion and dispersion due to different concentration. On testing days, each specimen was cut into $10 \mathrm{~mm}$ thick slices until reaching the midpoint of the cubes. The coating was removed from the edges and samples were left out for one day to dry. Each slice was ground to create concrete dust samples. Titration tests were used to measure chloride diffusion in the samples.

\section{Results and Discussion}

Sieve analyses of natural (NA) and recycled (RA) aggregates are shown in Figures 1 and 2. It can be observed from both figures that the grading for natural (NA) and recycled (RA) aggregates is almost the same. Therefore, it can be concluded that recycled aggregate (in our study) produced by using a jaw crusher is within the requirements of ASTM-C33 [22].

The effect of the percentage of recycled aggregates on the compressive strength of concretes (with error bar and standard deviations) is shown in Figure 3. The strength value fluctuates slightly with the percentages of recycled aggregate from 24.63 to $21.682 \mathrm{MPa}$ for $0 \%$ and $100 \%$ recycled aggregates, respectively, and reaching a maximum of 25.02 $\mathrm{MPa}$ for $40 \%$ recycled aggregates. These results indicate that recycled aggregates can be used with confidence in concrete mixes.

Variations of slump and unit weight of fresh concrete with respect to aggregate concentration are presented in Figure 4 . The fresh concrete's workability, defined as the ease with which concrete can be mixed, transported, and placed, is affected by the interactions of recycled and natural aggregates. As shown in Figure 5, the slump for all mixes fluctuates slightly over the minimum value for recycled aggregate concentrations; however, it reached a maximum value when the recycled aggregate concentration was $20 \%$. In general, the recycled aggregate concrete specimens exhibit acceptable workability in terms of ease of handling, placement, and finishing.

The unit weight of the concrete ranged from 2365 to $2175 \mathrm{~kg} / \mathrm{m}^{3}$, depending on aggregate content (Figure 6). Increasing the recycled aggregate content reduces the unit weight and density of the concrete, resulting in lighter concrete (Figure 6). The unit weights of the 15\%, 20\%, and $25 \%$ mixes were reduced by $8 \%, 11 \%$, and $11.5 \%$, respectively, compared to plain concrete. The unit weight reduction is a result of the lower unit weight of recycled aggregates replacing the much heavier natural aggregates. It could also be due to the old cement paste attached to the recycled aggregate. Therefore, recycled aggregate concrete is expected to be more porous than plain concrete. A smaller reduction in unit weight, compared to those of the $20 \%$ to $100 \%$ mixes, was realized for the $10 \%$ mixes. 


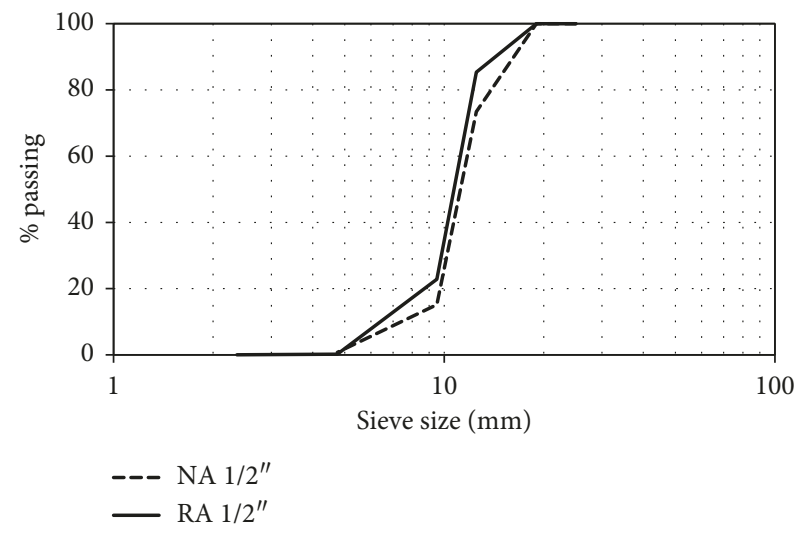

FIGURE 1: Grading of natural and recycled 1/2" coarse aggregates.

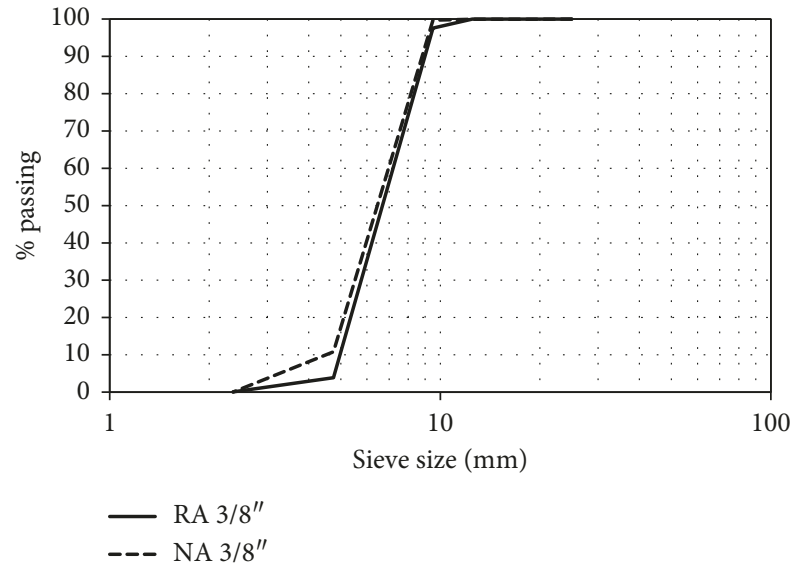

FIGURE 2: Grading of natural and recycled $3 / 8^{\prime \prime}$ coarse aggregates.

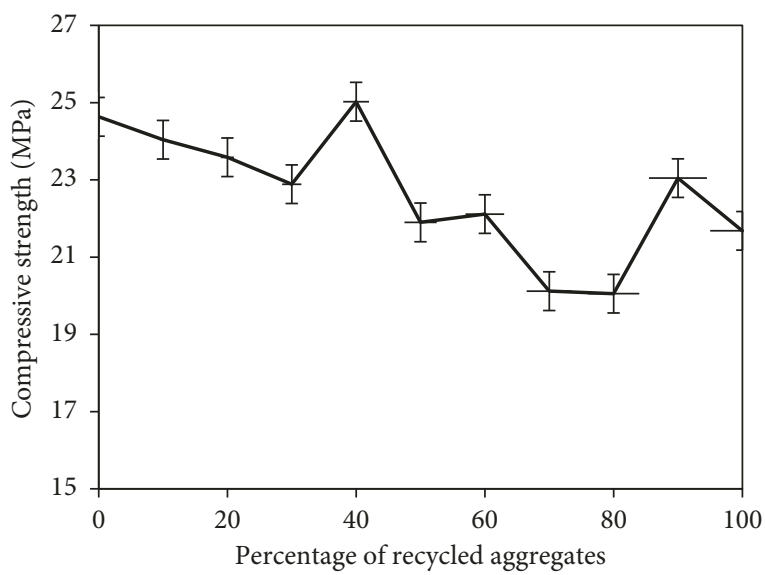

Figure 3: Compressive strength for all mixes after 28 days.

The air content for the different percentages of aggregate mixes is shown in Figure 7; it is within the range of $1.6 \%$ to $2.5 \%$. Increasing the recycled aggregate content did not cause large variations in air content. For $0 \%$ and $100 \%$ recycled aggregate mixes, the air content was $2.5 \%$ and $2 \%$, respectively.

Figures 8 and 9 present the results of water absorption and moisture content, respectively, for the different mixes.

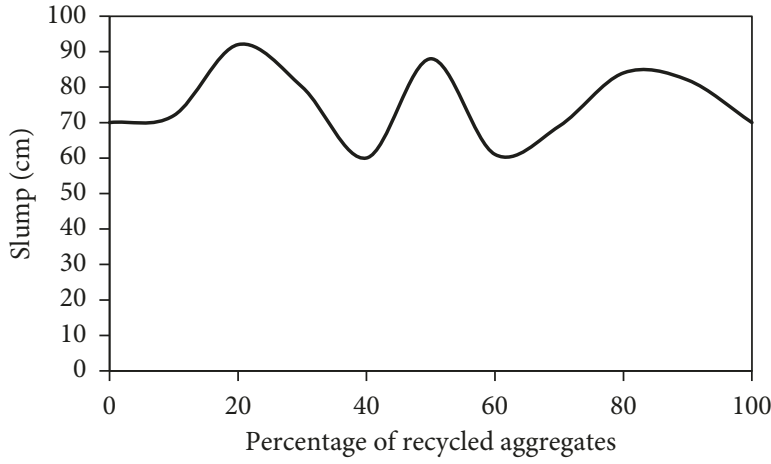

FIGURE 4: Slump test results for all mixes.

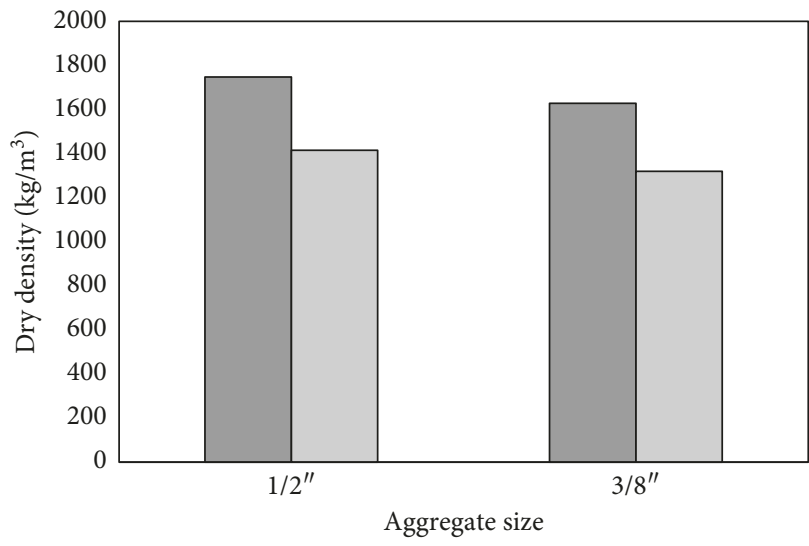

口 Natural aggregates

$\square$ Recycled aggregates

FiguRE 5: Dry densities of natural and recycled aggregates.

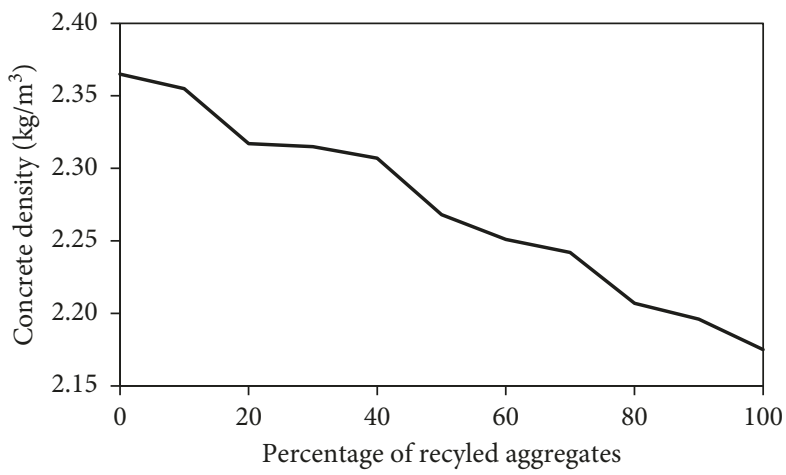

Figure 6: Unit weights of different mixes.

Water absorption and moisture content are increasing as the recycled aggregate replacement increases. This could be attributed to the increase of voids within the mix in the case of replacement of natural aggregates with recycled aggregates. Moreover, the number of voids could increase because of the weaker bonding between the recycled aggregate particles and the cement and natural aggregate. Therefore, when the mixes are undergoing curing, water will fill the voids, resulting in increased water absorption. In addition, the water absorption of the recycled aggregate is dependent 


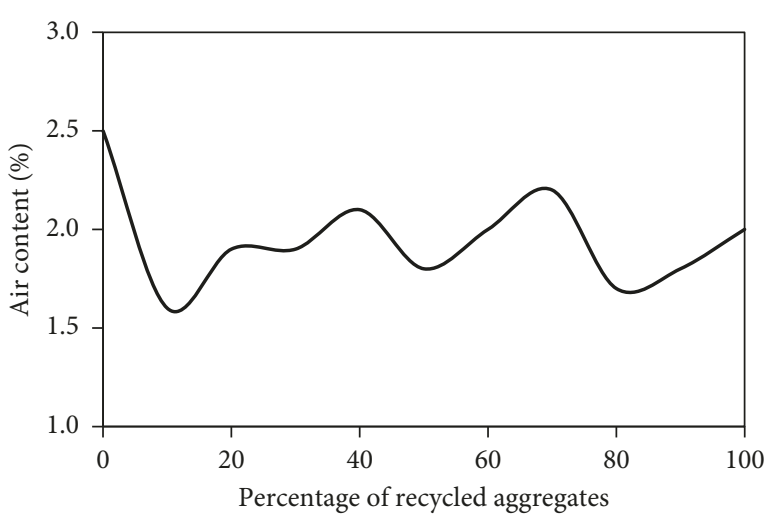

Figure 7: Air content for all mixes.

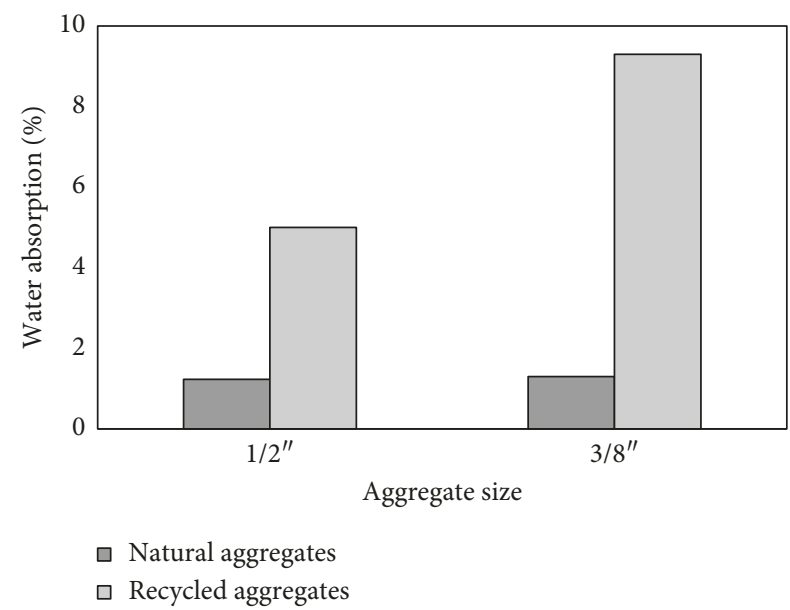

FIgURE 8: Water absorption of natural and recycled aggregates.

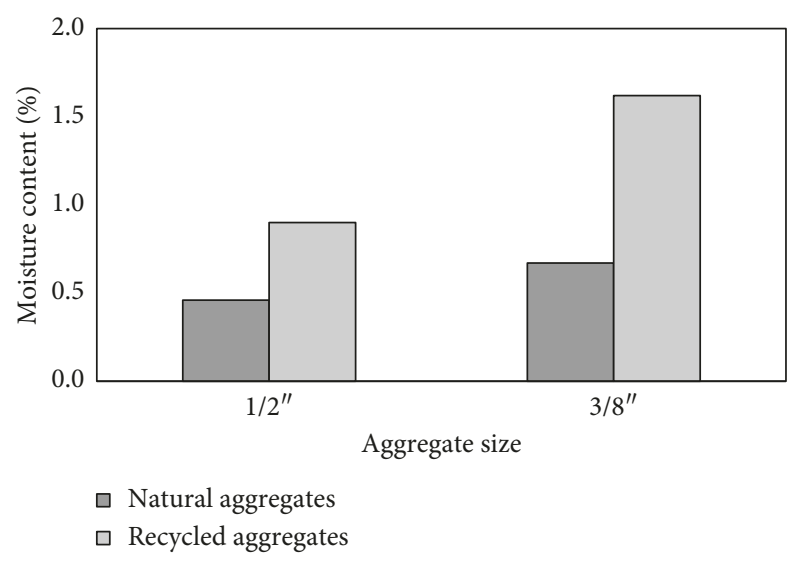

FIgURE 9: Moisture content of natural and recycled aggregates.

on the size of the aggregate and increases when the size of the recycled aggregate increases.

4.1. Chloride Effects. Samples were exposed to chloride and tested after 2 and 4 weeks of exposure to sea water with 3\% chloride concentration. The results after 2- and 4-week exposure are shown in Figures 10 and 11, respectively.

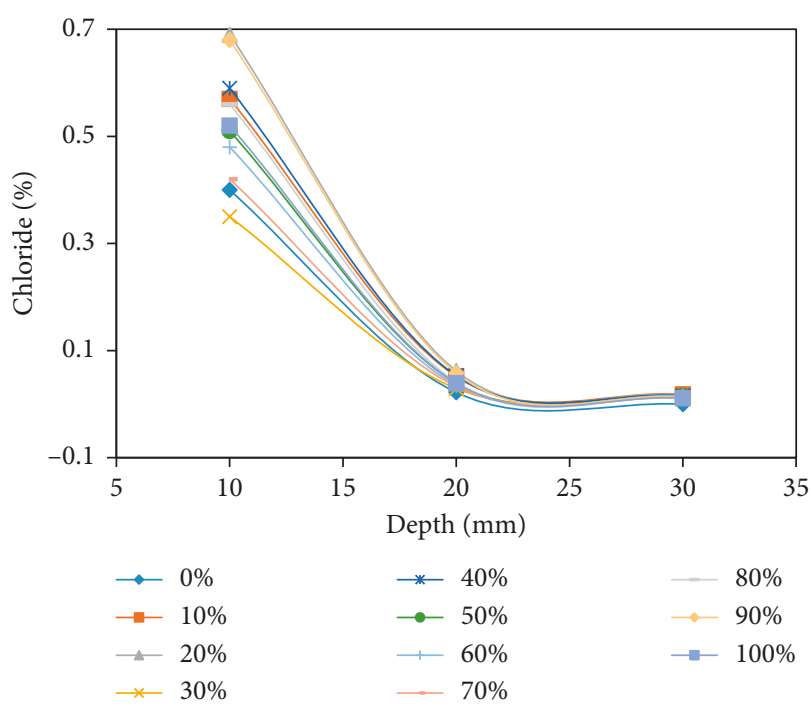

Figure 10: Chloride diffusion for all mixes after 2 weeks.

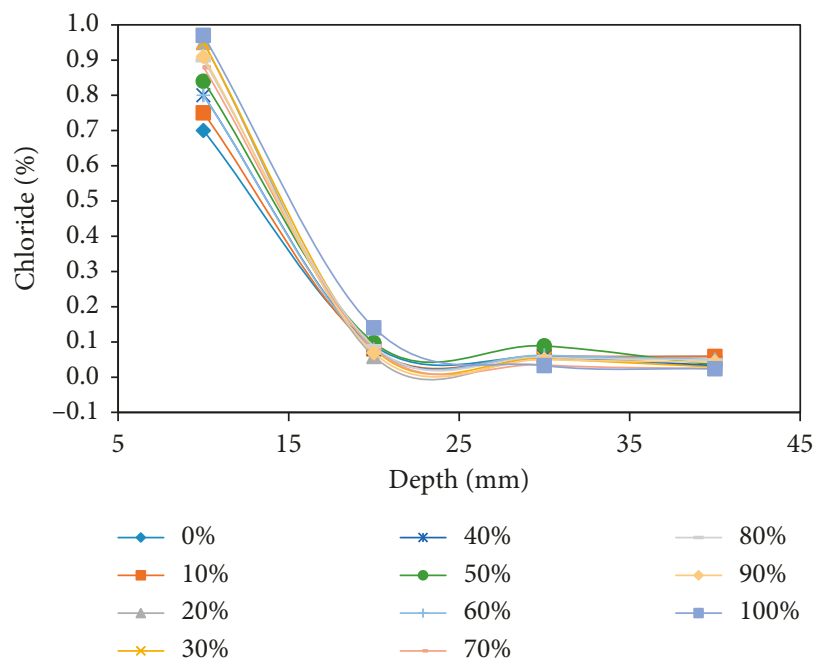

FIGURE 11: Chloride diffusion for all mixes after 4 weeks.

It can be observed that the concrete mix with $30 \%$ recycled aggregate experienced the least chloride penetration after 2 weeks and was actually better than the concrete mix with $100 \%$ natural aggregate. The chloride diffusion in the $70 \%$ recycled aggregate concrete was similar to the concrete mix with $100 \%$ natural aggregate. However, after 4 weeks of exposure to chloride, the results show that chloride diffusion increased with increasing recycled aggregate content.

\section{Conclusions and Recommendations}

There is a global need to protect our environment and preserve scarce natural resources for following generations. Recycling of construction and demolition materials can help preserve our public fill capacity and landfill space. It can also help us to reduce the need for quarrying and other damage caused to the natural landscape. Recycled aggregates can be used in many applications, including concrete production. 
This paper has presented various aspects regarding recycled aggregates and their use in concrete, which can be summarized as follows:

(1) Grading (sieve analysis) levels for natural and recycled aggregates are almost the same.

(2) Bulk densities of recycled aggregate are lower than natural aggregate, while the moisture content and water absorption of recycled aggregate mixes are higher than those of natural aggregate.

(3) The workability of concrete, expressed in terms of slump, varied within the range from 60 to $92 \mathrm{~mm}$, which is acceptable for new concrete.

(4) Both air content and density of concrete mixes were linear and decreased with increasing recycled aggregate content because the bulk density of recycled aggregate is less than the bulk density of natural aggregate.

(5) Compressive strength decreased with increasing recycled aggregate content. In addition, the concrete mix with $40 \%$ recycled aggregate exhibited the best compressive strength.

(6) Concrete mix with $30 \%$ recycled aggregate experienced the lowest chloride penetration after 2 weeks of saturation, which was better than the concrete mix with $100 \%$ natural aggregate. The chloride diffusion in concrete mix with $70 \%$ recycled aggregate was similar to the concrete mix with $100 \%$ natural aggregate.

(7) After 4 weeks of saturation in chloride, the results demonstrated that chloride diffusion increased with increasing recycled aggregate content.

This study has exclusively focused on the mechanical and physical properties of concrete for $1 / 2^{\prime \prime}$ and $3 / 8^{\prime \prime}$ aggregate replacement. There is a need for future studies to investigate other sizes of aggregate in concrete. This type of research can increase confidence in the use of recycled aggregates and thus widen their range of applications.

\section{Data Availability}

The data used to support the findings of this study are included within the article.

\section{Conflicts of Interest}

The authors declare that there are no conflicts of interest regarding the publication of this paper.

\section{References}

[1] F. Yuan, L.-Y. Shen, and Q.-M. Li, "Emergy analysis of the recycling options for construction and demolition waste," Waste Management, vol. 31, no. 12, pp. 2503-2511, 2011.

[2] G. Xu, W. Shen, B. Zhang, Y. Li, X. Ji, and Y. Ye, "Properties of recycled aggregate concrete prepared with scattering-filling coarse aggregate process," Cement and Concrete Composites, vol. 93, pp. 19-29, 2018.
[3] J. Wang, H. Yuan, X. Kang, and W. Lu, "Critical success factors for on-site sorting of construction waste: a China study," Resources, Conservation and Recycling, vol. 54, no. 11, pp. 931-936, 2010.

[4] N. Kartam, N. Al-Mutairi, I. Al-Ghusain, and J. Al-Humoud, "Environmental management of construction and demolition waste in Kuwait," Waste Management, vol. 24, no. 10, pp. 1049-1059, 2004.

[5] K. Rahal, "Mechanical properties of concrete with recycled coarse aggregate," Building and Environment, vol. 42, no. 1, pp. 407-415, 2007.

[6] J. Thomas, N. N. Thaickavil, and P. M. Wilson, "Strength and durability of concrete containing recycled concrete aggregates," Journal of Building Engineering, vol. 19, pp. 349-365, 2018.

[7] A. S. Abdel-Hay, "Properties of recycled concrete aggregate under different curing conditions," HBRC Journal, vol. 13, no. 3, pp. 271-276, 2017.

[8] C.-S. Poon, S.-C. Kou, H.-W. Wan, and M. Etxeberria, "Properties of concrete blocks prepared with low grade recycled aggregates," Waste Management, vol. 29, no. 8, pp. 2369-2377, 2009.

[9] V. B. M. Kumar, H. Ananthan, and K. V. A. Balaji, "Experimental studies on utilization of recycled coarse and fine aggregates in high performance concrete mixes," Alexandria Engineering Journal, vol. 57, no. 3, pp. 1749-1759, 2018.

[10] R. Muduli and B. B. Mukharjee, "Effect of incorporation of metakaolin and recycled coarse aggregate on properties of concrete," Journal of Cleaner Production, vol. 209, pp. 398414, 2019.

[11] K. Falek, K. Aoudjane, E. H. Kadri, and F. Kaoua, "Influence of recycled aggregates on the mechanical and tribological behavior of concrete," Energy Procedia, vol. 139, pp. 456-461, 2017.

[12] P. S. Lovato, E. Possan, D. C. C. D. Molin, Â. B. Masuero, and J. L. D. Ribeiro, "Modeling of mechanical properties and durability of recycled aggregate concretes," Construction and Building Materials, vol. 26, no. 1, pp. 437-447, 2012.

[13] J. V. Puthussery, R. Kumar, and A. Garg, "Evaluation of recycled concrete aggregates for their suitability in construction activities: an experimental study," Waste Management, vol. 60, pp. 270-276, 2017.

[14] M. Maslehuddin, M. M. Al-Zahrani, M. Ibrahim, M. H. AlMehthel, and S. H. Al-Idi, "Effect of chloride concentration in soil on reinforcement corrosion," Construction and Building Materials, vol. 21, no. 8, pp. 1825-1832, 2007.

[15] K. P. Verian, W. Ashraf, and Y. Cao, "Properties of recycled concrete aggregate and their influence in new concrete production," Resources, Conservation and Recycling, vol. 133, pp. 30-49, 2018.

[16] T. Zhang and O. E. Gjorv, "Effect of chloride source concentration on chloride diffusivity in concrete," ACI materials journal, vol. 102, pp. 295-298, 2005.

[17] F. T. Olorunsogo and N. Padayachee, "Performance of recycled aggregate concrete monitored by durability indexes," Cement and Concrete Research, vol. 32, no. 2, pp. 179-185, 2002.

[18] R. Neves, A. Silva, J. de Brito, and R. V. Silva, "Statistical modelling of the resistance to chloride penetration in concrete with recycled aggregates," Construction and Building Materials, vol. 182, pp. 550-560, 2018.

[19] M. Buhamad, Effect of Recycled Aggregate on the Chloride Diffusion in Fully Saturated Concrete, Kuwait University, Kuwait City, Kuwait, 2012. 
[20] J. Xiao, J. Ying, and L. Shen, "FEM simulation of chloride diffusion in modeled recycled aggregate concrete," Construction and Building Materials, vol. 29, pp. 12-23, 2012.

[21] M. Arezoumandi, A. R. Steele, and J. S. Volz, "Evaluation of the bond strengths between concrete and reinforcement as a function of recycled concrete aggregate replacement level," Structures, vol. 16, pp. 73-81, 2018.

[22] ASTM C33/C33M, Standard Specification for Concrete Aggregates, ASTM International, West Conshohocken, PA, USA, 2012. 


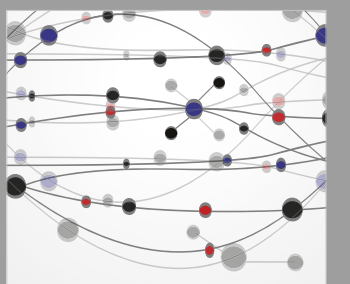

The Scientific World Journal
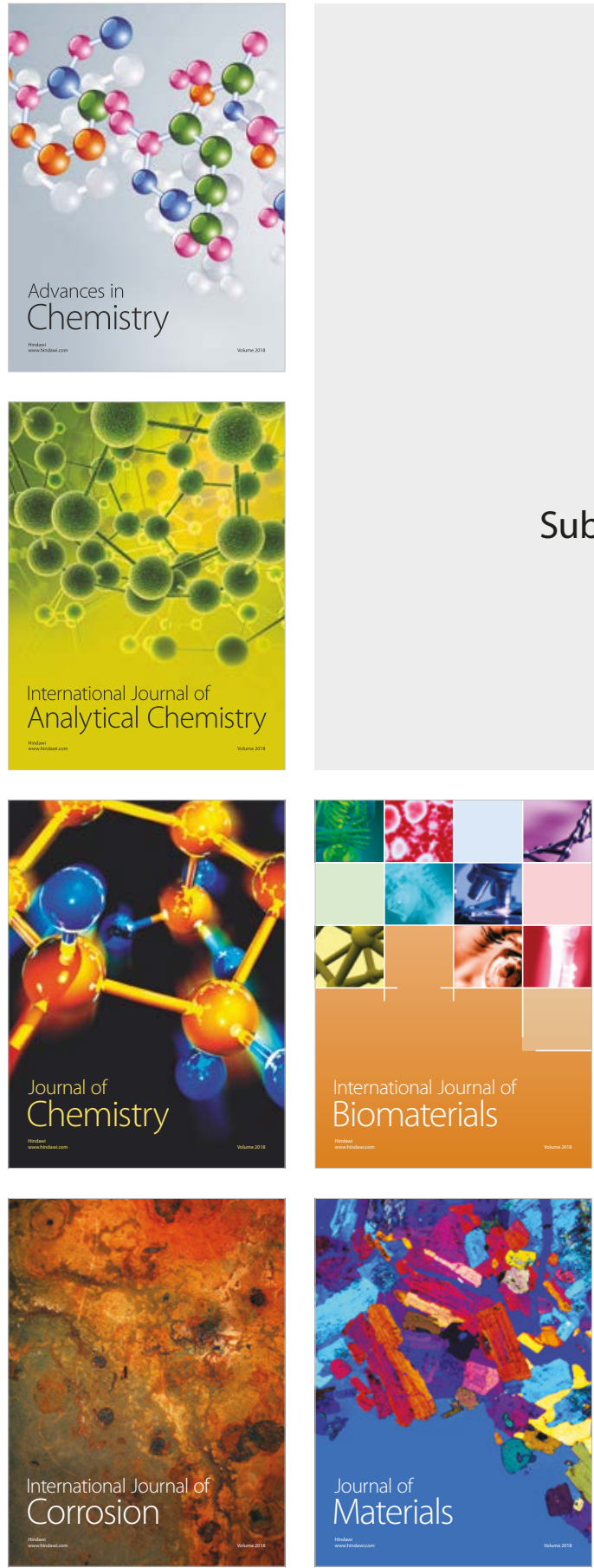

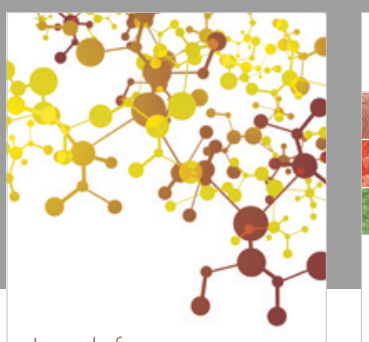

Journal of

Applied Chemistry
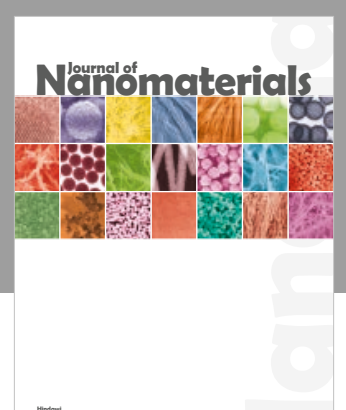

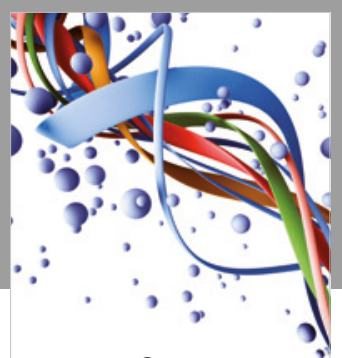

Scientifica

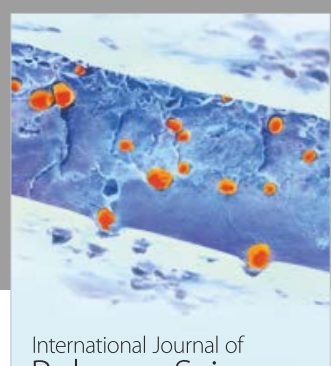

Polymer Science

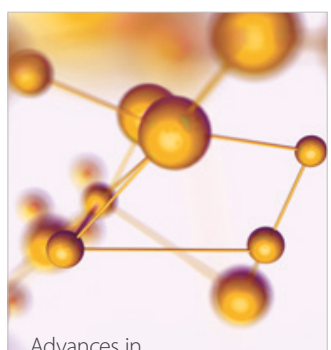

Physical Chemistry
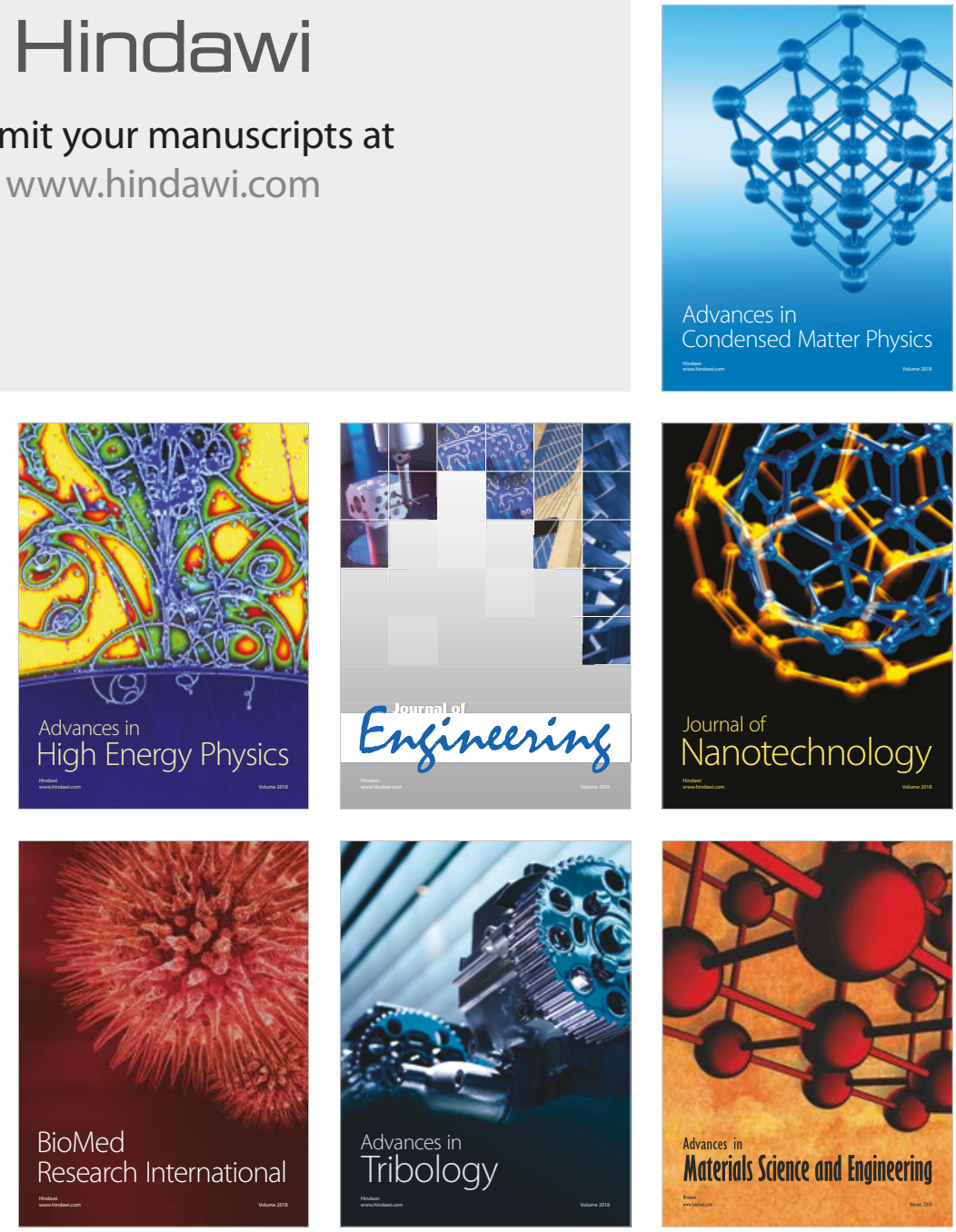